\title{
Preparation and characterization of herbal emulsion formulations
}

\author{
Sakine TUNCAY TANRIVERDİ, Evren ALGIN YAPAR
}

\begin{abstract}
St John's wort extract (Hypericum perforatum L. aerial part extract), marigold extract (Calendula officinalis $L$. flower extract), wheat germ oil (Triticum vulgare Vill. germ oil) and rose oil (Rosa damascena Mill. volatile oil) have antiinflammatory, antimicrobial and wound healing properties. In this study, it is aimed to prepare and characterize herbal topical emulsion formulations for skin disorders with these herbal extracts and oils. Initially the compatibility of herbal ingredients was evaluated and the design of formulation as an emulsion was studied. Then decided cream formulations were prepared as
\end{abstract}

$\mathrm{o} / \mathrm{w}$ type emulsions. The formulations characterized via several parameters such as; macroscopic and microscopic observations, $\mathrm{pH}$, electrical conductivity and rheological measurements. The characterization of prepared three formulations revealed acceptable properties while one of them had better applicability, maintained its macroscopic stability in room conditions for 6 months, had appropriate $\mathrm{pH}$ and electrical conductivity values and had pseudoplastic flow properties. As conclusion, a topical emulsion formulation was prepared with appropriate properties.

Keywords: Topical delivery; herbal formulations; emulsion; St John's wort extract; marigold extract.
Sakine Tuncay Tanriverdi

Ege University, Faculty of Pharmacy, Department of Pharmaceutical Technology, PK 35100, Bornova/İzmir, Türkiye

Evren Algin Yapar

Republic of Turkey Ministry of Health, Turkish Medicines and Medical Devices Agency, Söğütözü Mahallesi 2176.Sokak No:5 PK 06520 Çankaya/Ankara, Türkiye

Corresponding Author:

Evren Algin Yapar

e-mail:evren.yapar@yahoo.com

Submitted / Gönderilme: 24.01.2017 Revised / Düzeltme: 11.05.2017 Accepted / Kabul: 19.05.2017

How to cite this article: Tuncay Tanrıverdi S, Algın Yapar E. Preparation and characterization of herbal emulsion formulations. Marmara Pharm J 2017; 21 (4): 756-761

\section{INTRODUCTION}

The appropriate vehicle for topical delivery has to be chosen to obtain optimum effectiveness from active ingredients. During the recent decades various topical systems have been investigated as suitable pharmaceutical vehicles for successful dermal and transdermal delivery of active substances. Emulsion has several advantages such as enhanced drug solubility, ease of manufacturing and enhancement effect on transdermal delivery over conventional formulation such as gel and ointments. An emulsion system consists of oil phase, water phase and surfactant or surfactants mixture. In this study, emulsion formulations were prepared with oil mixtures that have synergistic effect on skin disorders.

Topical application of St John's wort (Hypericum perforatum L.) extract [1], marigold (Calendula officinalis L.) extract [2, 3], wheat (Triticum vulgare L.) germ oil [4] and rose (Rosa damascena $L$.) oil [5] for various topical treatment approaches due to anti-inflammatory, antimicrobial and healing effects indicated in scientific literatures. In this direction, combination of above mentioned herbal ingredients together in a formulation, which is cosmetically acceptable, stable, easily prepared and applicable, will be useful for the skin 
disorders. In case of topical application of herbal substances, emulsions have offer formulation advantages due to their structure available as both aqueous and oily substances and being cosmetically acceptable [5-10].

The aim of this study was to design new emulsion formulations with herbal oils and extract for treatment of skin disorders. The formulations were characterized via several parameters such as; macroscopic and microscopic observations, $\mathrm{pH}$, electrical conductivity and rheological measurements.

\section{MATERIALS AND METHODS}

\subsection{Materials}

Hypericum perforatum L. aerial part extract, Calendula officinalis $L$. flower extract, Rosa damascena Mill. volatile oil (Muğla Sitkı Koçman University, Muğla, Turkey), Triticum vulgare Vill. germ oil (Bezmialem VakıfUniversity, Bezmialem center of Education, Practice and Research in Phytotherapy, İstanbul, Turkey), liquid paraffin, cetyl alcohol, Tween $80^{\circ}$ (Merck KGaA, Darmstadt, Germany), Span $80^{\circ}$ (Fluka, Buchs, Germany), Carbopol 974 (Corel Pharma Chem., Gujarat, India), hydroxypropyl methylcellulose (Colorcon, Dartford, UK), ascorbyl palmitate (Sigma-Aldrich Chemie $\mathrm{GmbH}$, Germany), phenoxyethanol caprylyl glycol (Kale Kimya A.Ş., Kocaeli, Turkey), and de-ionized (DI) water was obtained from ultrapure water system (Model-Arium 611) of Sartorius AG (Goettingen, Germany).

\subsection{Preparation of Formulations}

Compatibility of herbal contents is evaluated by preformulation studies in the light of related articles. The effect of parameters such as the content of surfactant, oil, herbal extracts, HLB number of surfactant blend and additive content on emulsion stability was studied by trial and error method [9-11]. Formulations with selected herbal ingredients were prepared by the emulsion method to obtain $\mathrm{o} / \mathrm{w}$ emulsion formulations. St John's wort extract, marigold extract, wheat germ oil, rose oil, ascorbyl palmitate, cetyl alcohol, liquid paraffin were used as oil phase [9]. Span $80^{\circ}$ was used as hyrophobic surfactant and mixed with oil phase with a magnetic stirrer (RH basic, IKA, Staufen, Germany). Distilled water that mixed Tween $80^{\circ}$ (hydrolic surfactant) and phenoxyethanol caprylyl glycol (preservative) was used as water phase of emulsions. Formulations were prepared by adding water phase to oil phase while mixing by mechanic stirrer (IKA RW 20, Staufen, Germany) at $1000 \mathrm{rpm}$ for
$30 \mathrm{~min}$ at room temperature. The emulsion was mixed for $30 \mathrm{~min}$ more to obtain stable formulations. Carbopol $974^{\circ}$ or hydroxypropyl methylcellulose (HPMC) was added to the water phase for F1 and F2 formulations, respectively. F3 formulation was prepared without any gelling agent. Formulations with their contents are presented below in Table 1.

The HLB of emulsion formulation blend of tween 80 $(\mathrm{HLB}=15)$ and span $80(\mathrm{HLB}=4.3)$ was calculated according equation. $\mathrm{Wa}$ and $\mathrm{Wb}$ are weights of Tween 80 and Span 80 in the formulation, respectively.

$$
H L B \operatorname{mix}=\frac{(W a \times H L B a)+(W b+H L B b)}{W a+W b}
$$

Table 1. Contents with their amounts as gram for three emulsion formulations coded as F1, F2 and F3 are presented.

\begin{tabular}{|l|l|l|l|}
\hline Contents & F1 & F2 & F3 \\
\hline Liquid paraffin & 12.5 & 12.5 & 12.5 \\
Cetyl alcohol & 10 & - & 5 \\
Tween $80^{\circ}$ & 0.64 & 0.44 & 0.64 \\
Span $80^{\circ}$ & 0.36 & 0.36 & 0.34 \\
Carbopol 974 & 0.25 & - & - \\
HPMC & - & 0.5 & - \\
Distilled water & 15 & 15.95 & 15.75 \\
Phenoxyethanol caprylyl glycol & 0.25 & 0.25 & 0.25 \\
Hypericum perforatum L. extract & 3.5 & 7.5 & 5.5 \\
Calendula officinalis L.extract & 3.5 & 7.5 & 5 \\
Rosa damascena L. oil & 1 & 1 & 1 \\
Triticum vulgare L.oil & 1.5 & 2 & 2 \\
Ascorbyl palmitate & 1.5 & 2 & 2 \\
\hline Total amount & $\mathbf{5 0}$ & $\mathbf{5 0}$ & $\mathbf{5 0}$ \\
\hline
\end{tabular}

\subsection{In vitro Characterization Studies}

Characterization studies were performed with the macroscopic and microscopic observations, measurement of $\mathrm{pH}$, and determination of rheological behavior, electrical conductivity and stability of the formulations. Stability observations were performed under room conditions $(25 \pm 1$ ${ }^{\circ} \mathrm{C}$ ) for 6 months in terms of macroscopic observations.

\section{Microscopic observation}

The microscopic observation of the formulations was examined and photographed by using an optical microscope (Olympus CH40) to show particular structure of emulsion systems. The type of formulation (o/w or w/o) could be 
observed by this method. Methylene blue could dissolve in water and the solution of methylene blue was used to dye water phase of emulsions. All slides were dyed and then covered by glass. The microscope samples were examined at room temperature under $\mathrm{x} 10$ magnification.

\section{Measurement of $\mathrm{pH}$}

The $\mathrm{pH}$ values of the formulations were determined by using a pH meter (Jenway 3040 Ion Analyzer, U.K.) at $25 \pm 1^{\circ} \mathrm{C}$. All experiments were replicated three times.

\section{Measurement of electrical conductivity}

The electrical conductivity $(\sigma)$ of formulations was measured by using a conductivity meter (Jenway, 4071 , U.K.) at $25 \pm 1$ ${ }^{\circ} \mathrm{C}$. All experiments were replicated three times.

\section{Rheological measurements}

The rheological analysis of the formulations was performed at $25 \pm 0.1^{\circ} \mathrm{C}$ using an AR 2000 controlled stress/controlled rate rheometer (Haake MARS, platte PP35 Ti, plate cover MPC35, Karlsruhe, Germany). In continuous shear analysis, the upward and downward flow curves for each formulation were measured over shear rates ranging from 10 to $900 \mathrm{~s}^{-1}$. All experiments were replicated at three times.

\section{RESULTS and DISCUSSION}

\subsection{Preparation of Formulations}

After pre-formulation study three formulations were prepared successfully. The HLB values of formulations were found $11.148,10.185$ and 11.287 for F1, F2 and F3 formulations, respectively. The HLB system is particularly useful to identify surfactants for oil and water emulsification. There are two basic emulsion types. One is water-in-oil (w/o) that water is dispersed in oil phase and other is oil-in-water $(\mathrm{o} / \mathrm{w})$ that oil is dispersed in aqueous phase. Water-in-oil emulsions (w/o) require low HLB surfactants. Oil-in-water $(\mathrm{o} / \mathrm{w})$ emulsions often require higher HLB surfactants that are more than ten [12]. Our results were showed that the type of formulations is oil in water. But the values are at limit which confirms the formulations are not so oily or water base.

The macroscopic observation results showed that all the formulations were uniform, had light pink color, and did not present any incompatibility in terms of herbal ingredients. The main stability problems of emulsions are creaming, sedimentation, flocculation, phase inversion and coalescence [13]. To use herbal oil blend as oil phase is main difficulty of preparing stabilized emulsion formulation. Stability observations did not demonstrate any significant change for 6 months during the macroscopic characterization of formulations. It was concluded that the herbal oil blend could use to prepare emulsion type formulations.

\subsection{Measurement of $\mathrm{pH}$}

The pHs of formulations were 3.94, 4.64 and 4.94 for F1, F2 and F3, respectively. High oil content of formulations could affect the $\mathrm{pH}$ of formulations due to acidic compositions of oils. The $\mathrm{pH}$ of topical formulations for dermal delivery should be around five [14]. The $\mathrm{pH}$ values of all formulations were compatible with the skin $\mathrm{pH}$ value. But as it was seen, F1 and F2 have low values than F3 that is more compatible for skin.

\subsection{Measurement of electrical conductivity}

The electrical conductivity of formulations is measured to show if the formulations are w/o or o/w. For w/o emulsion system, the electrical conductivity cannot be measured. Because, oil phase could inhibits conductivity. Desirable electrical conductivity results were obtained from formulation depends on their composition and conductivity values, which were found as $51.2,55.9$ and $9.1 \mu \mathrm{S} / \mathrm{cm}$ for F1, F2 and F3, respectively. All results are acceptable for skin application. The electrical conductivity measurements showed that all formulations were o/w systems as confirmed also with HLB calculation results.

\subsection{Microscopic observation}

The results of microscopic observations, which are presented in Figure 1 confirmed that the emulsion systems were performed and F3 formulation was more uniform than F1 and F2 formulations. Blue external phase showed that all the systems are oil in water system. Low polydispersity of F3 confirmed high long term stability of formulation.

The polymeric substances could use to increase stability of emulsion formulations [15]. These substances could increase the viscosity of emulsion and decrease coalescences of emulsion droplets. In this study, F3 formulation was prepared without polymeric substance while F1 was prepared with carbopol and F2 was prepared with hydroxylpropylmethyl cellulose. The microscopic images of F1 and F2 are cloudy due to polymeric structure of formulations. 

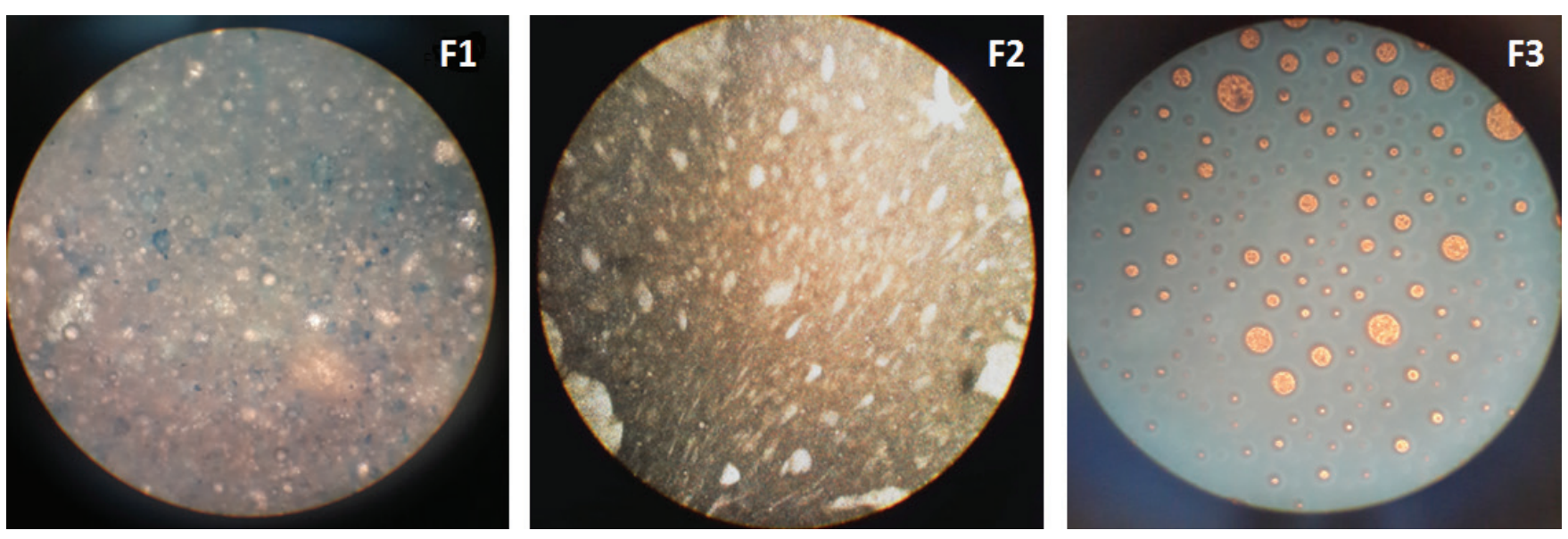

Figure 1. The microscopic images of F1, F2 and F3 formulations.

\subsection{Rheological measurements}

Rheological studies carried out in order to test the viscosity and flow properties of formulations. The rheological properties of topical formulations affect both the ease of application and spreadability on skin surface. As shown in Figure 1, viscosity decreases with increasing shear rate, as expected from pseudoplastic fluids. And also, the shear stress changes upon shear rates have been used to determine whether the rheological behavior of the formulation is Newtonian or non-Newtonian [16]. It was shown that all the formulations exhibited pseudoplastic flow property at $25^{\circ} \mathrm{C}$ (Figure 2 and Figure 3). When the starting point of viscosity values compared it was seen that $\mathrm{F} 1$ formulation has higher viscosity than F2 and F3. But F3 formulation, without polymer, has higher viscosity than F2. It was thought that cetyl alcohol, a solid lipid, affected viscosity of formulations. Because F1 formulation was prepared with $20 \%$, F3 was prepared with $5 \%$ and F2 was prepared without cetyl alcohol. The flow behavior of formulations are close each other due to similar formulation composition. By the way, the greatest degree of pseudoplasticity was exhibited with F1 formulation.



Figure 2. Viscosity versus shear rate curves of F1, F2 and F3 formulations. 


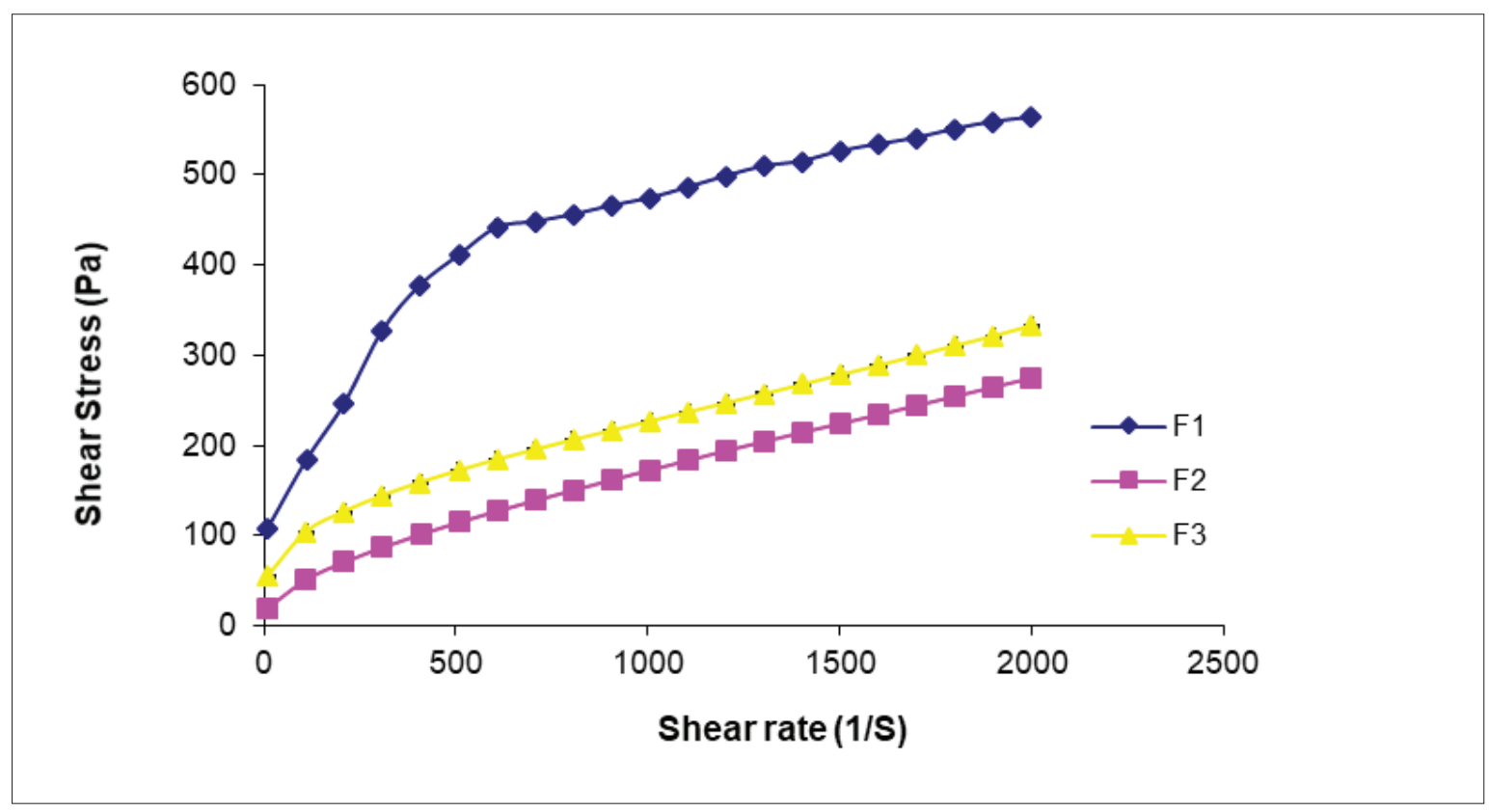

Figure 3. Flow curves of F1, F2 and F3 formulations.

The next step of this study is to perform detailed stability and dermatological tests on the final formulation after accomplishing the formulation development studies for F3.

\section{CONCLUSION}

Emulsion formulations have many advantages for topical application of active ingredients. In our study, emulsion formulations were prepared with herbal ingredients such as; St John's wort extract, marigold extract, wheat germ oil and rose oil. These extracts and oils are useful for skin disorders as inflammation, wounds and microbial infection. According to aim of this study, three emulsion formulations were prepared successfully. The formulations were characterized via several parameters. All the formulations have acceptable criteria for topical application of herbal substances. But, F3, formulation without polymer, were chosen for further studies due to microscopic observation and $\mathrm{pH}$ measurement study results. For further studies, stability studies are going on and dermatologic activity of formulations will be evaluated as clinical study.

\section{REFERENCES}

1. Wölfle U, Seelinger G, Schempp CM. Topical Application of St. John's Wort (Hypericum perforatum). Planta Med 2014; 80: 109-20.

2. Hamburger M, Adler S, Baumann D, Förg A, Weinreich B. Preparative purification of the major anti-inflammatory triterpenoid esters from Marigold (Calendula officinalis). Fitoterapia 2003; 74: 328-38.

3. Roveroni-Favaretto LHD, Lodi KB, Almeida JD. Topical Calendula officinalis $L$. successfully treated exfoliative cheilitis: a case report. Cases J 2009; 23: 9077.

4. Cosmetic Dermatology: Principles and Practice. Editor: Baumann L. The McGraw-Hill Companies, Inc. Chine. 2009, pp 294.

5. Alğın Yapar E, İnal Ö, Erdal S. Design and in vivo evaluation of emulgel formulations including green tea extract and rose oil. Acta Pharm 2013: 63; 531-44.

6. Ho KM. Proper choice of base of topical medicaments. Med Bull 2006; 11: 7-8.

7. Dhase AS, Khadbadi SS, Saboo SS. Formulation and evaluation of vanishing herbal cream of crude drugs. AJEthno 2014; 1: 313-8.

8. Gade J, More S, Bhalerao N. Formulation and characterization of herbal cream containing Fenugreek seed extracts. Int J Sci Res 2015; 5: 1-4. 
9. Mishra AP, Saklani S, Milella L, Tiwari P. Formulation and evaluation of herbal antioxidant face cream of Nardostachys jatamansi collected from Indian Himalayan region. Asian Pac J Trop Biomed 2014; 4: 679-82.

10. Thakur L, Ghodasra U, Patel N, Dabhi M. Novel approaches for stability improvement in natural medicines. Pharmacogn Rev 2011; 5: 48-54.

11. Shrikumar S, Maheshwari U, Sughanti A, Ravi TK. WHO guidelines for herbal drug standardization, 2006.

12. Schmidts T, Dobler D, Guldan A-C, Paulus N, Runkel F. Multiple W/O/W emulsions-using the required HLB for emulsifier evaluation. Colloids Surf A Physicochem Eng Asp
2010; 372: 48-54.

13. Tadros TF, Vincent B. Encyclopedia of Emulsion Technology Editor: Becher P. Marcel Dekker, New York. 1983.

14. Lambers H, Piessens S, Bloem A, Pronk H, Finkel P. Natural skin surface $\mathrm{pH}$ is on average below 5 , which is beneficial for its resident flora. Int J Cosmet Sci 2006; 28:359-70.

15. Amit M, Stavans J. Stability of emulsions with nonadsorbing polymers. Langmuir 1996; 12: 301-4.

16. Tanriverdi ST, Özer Ö. Novel topical formulations of terbinafine- $\mathrm{HCl}$ for treatment of onychomycosis. Eur J Pharm Sci 2013;48:628-36. 